\title{
Erratum to: Palmitate induces a pro-inflammatory response in human pancreatic islets that mimics $C C L 2$ expression by beta cells in type 2 diabetes
}

\author{
M. Igoillo-Esteve $\cdot$ L. Marselli $\cdot$ D. A. Cunha • \\ L. Ladrière $\cdot$ F. Ortis $\cdot$ F. A. Grieco $\cdot$ F. Dotta $~$ \\ G. C. Weir • P. Marchetti • D. L. Eizirik • M. Cnop
}

Published online: 15 December 2011

(C) Springer-Verlag 2011

\section{Erratum to: Diabetologia}

DOI 10.1007/s00125-010-1707-y

Unfortunately the incorrect forward and reverse primer sequences for human $C X C L 1, C C L 2$ and $I L-1 \beta$ were listed in ESM Table 2 of this paper. The corrected sequences are shown in red in the table linked to this erratum.

The online version of the original article can be found at http:// dx.doi.org/10.1007/s00125-010-1707-y.

Electronic supplementary material The online version of this article (doi:10.1007/s00125-011-2389-9) contains peer-reviewed but unedited supplementary material, which is available to authorised users.

M. Igoillo-Esteve $\cdot$ D. A. Cunha $\cdot$ L. Ladrière $\cdot$ F. Ortis $\cdot$

D. L. Eizirik $\cdot$ M. Cnop $(\square)$

Laboratory of Experimental Medicine,

Université Libre de Bruxelles,

CP-618, Route de Lennik 808,

1070 Brussels, Belgium

e-mail: mcnop@ulb.ac.be

L. Marselli • P. Marchetti

Department of Endocrinology and Metabolism,

Metabolic Unit-University of Pisa,

Pisa, Italy

F. A. Grieco • F. Dotta

Department of Internal Medicine,

Endocrine and Metabolic Sciences and Biochemistry,

University of Siena and Umberto Di Mario Foundation,

Siena, Italy

G. C. Weir

Joslin Diabetes Center, Harvard Medical School,

Boston, MA, USA

\section{Cnop}

Division of Endocrinology, Erasmus Hospital,

Université Libre de Bruxelles,

Brussels, Belgium 